\title{
Impact of guideline-recommended versus non-guideline-recommended $\beta$-blocker and Doppler echocardiographic parameters on 1 -year mortality in Thai ischemic cardiomyopathy patients: A prospective multicenter registry
}

Nattawut Wongpraparut ${ }^{1 *}$ (D, Sarawut Siwamogsatham ${ }^{2}$, Tomorn Thongsri ${ }^{3}$, Pornchai Ngamjanyaporn ${ }^{4}$, Arintaya Phrommintikul ${ }^{5}$, Kompoj Jirajarus $^{6}$, Tarinee Tangcharoen ${ }^{7}$, Kid Bhumimuang ${ }^{8}$, Pinij Kaewsuwanna ${ }^{9}$, Rungroj Krittayaphong ${ }^{1}$, Rungtiwa Pongakasira ${ }^{10}$ and Harvey D. White ${ }^{11}$

\begin{abstract}
Background: Ischemic cardiomyopathy is a high-cost, resource-intensive public health burden that is associated with a 1-year mortality rate of about $16 \%$ in western population. Different in patient ethnicity and pattern of practice may impact the clinical outcome. We aim to determine 1-year mortality and to identify factors that significantly predicts 1-year mortality of Thai patients with ischemic cardiomyopathy.

Methods: This prospective multicenter registry enrolled consecutive Thai patients that were diagnosed with ischemic cardiomyopathy at 9 institutions located across Thailand. Patients with left ventricular function $<40 \%$ and one of the following criteria were included: 1) presence of epicardial coronary stenoses $>75 \%$ in the left main or proximal left anterior descending artery or coronary angiography, and/or two major epicardial coronary stenoses; 2) prior myocardial infarction; 3) prior revascularization by coronary artery bypass graft or percutaneous coronary intervention; or, 4) magnetic resonance imaging pattern compatible with ischemic cardiomyopathy. Baseline clinical characteristics, coronary and echocardiographic data were recorded. The 1-year clinical outcome was pre-specified.

Results: Four hundred and nineteen patients were enrolled. Thirty-nine patients (9.9\%) had died at 1 year, with 27 experiencing cardiovascular death, and 12 experiencing non-cardiovascular death. A comparison between patients who were alive and patients who were dead at 1 year revealed lower baseline left ventricular ejection fraction (LVEF) ( $26.7 \pm 7.6 \%$ vs $30.2 \pm 7.8 \% ; p=0.021$ ), higher left ventricular end-diastolic volume (LVEDV) (185.8 $\pm 73.2 \mathrm{ml}$ vs $155.6 \pm$ $64.2 \mathrm{ml} ; p=0.014)$, shorter mitral valve deceleration time $(142.9 \pm 57.5 \mathrm{ml} v \mathbf{1} 182.4 \pm 85.7 \mathrm{ml} ; p=0.041)$, and lower use of statins (94.7\% vs 99.7\%; $p=0.029$ ) among deceased patients. Patients receiving guideline-recommended $\beta$-blockers had lower mortality than patients receiving non-guideline-recommended $\beta$-blockers (8.1\% vs 18.2\%; $p=0.05$ ).

(Continued on next page)
\end{abstract}

\footnotetext{
* Correspondence: wongpraparut@yahoo.com

${ }^{1}$ Division of Cardiology, Department of Medicine, Faculty of Medicine Siriraj

Hospital, Mahidol University, 2 Wanglang Road, Bangkoknoi, Bangkok 10700,

Thailand

Full list of author information is available at the end of the article
}

(c) The Author(s). 2020 Open Access This article is distributed under the terms of the Creative Commons Attribution 4.0 International License (http://creativecommons.org/licenses/by/4.0/), which permits unrestricted use, distribution, and reproduction in any medium, provided you give appropriate credit to the original author(s) and the source, provide a link to the Creative Commons license, and indicate if changes were made. The Creative Commons Public Domain Dedication waiver (http://creativecommons.org/publicdomain/zero/1.0/) applies to the data made available in this article, unless otherwise stated. 
(Continued from previous page)

Conclusions: The results of this study revealed a 9.9\% 1-year mortality rate among Thai ischemic cardiomyopathy patients. Doppler echocardiographic parameters significantly associated with 1-year mortality were LVEF, LVEDV, mitral E velocity, and mitral valve deceleration time. The use of non-guideline-recommended $\beta$-blockers rather than guideline recommended $\beta$ blockers were associated with increased with 1-year mortality. Guidelines recommended $\beta$-blockers should be preferred.

Trial registration: Thai Clinical Trials Registry TCTR20190722002. Registered 22 July 2019. "Retrospectively registered".

Keywords: Thailand guideline-recommended $\beta$-blocker, Doppler echocardiography, 1-year mortality, Ischemic cardiomyopathy

\section{Background}

The term ischemic cardiomyopathy was introduced by Burch, et al. in 1970 to describe the cause and effect relationship between coronary artery disease (CAD) and severe myocardial dysfunction [1]. Left ventricular (LV) dysfunction from CAD called "ischemic cardiomyopathy" may not only be caused by an acute event such as myocardial infarction (MI) or a consequent from prior MI and scar formation but also may be caused by prolonged ischemia due to chronic CAD and hibernating myocardium [2, 3]. Mortality caused by acute coronary syndrome has decreased significantly over the last 20 years due to advancements in medical, interventional, and surgical treatment. Early reperfusion in ST-elevation myocardial infarction (STEMI) decreases mortality, reduces cardiogenic shock, and preserves LV function [4-9]. However, data from a Thai percutaneous coronary intervention (PCI) registry revealed that a substantial proportion of STEMI patients do not receive timely reperfusion therapy [9]. Patients that fail to receive timely reperfusion therapy, but survive STEMI are likely to develop LV dysfunction due to ischemic cardiomyopathy. Ischemic cardiomyopathy is a high-cost, resource-intensive public health burden that is associated with a 5-year mortality rate of about $40 \%$ [10]. Our review of the literature revealed no published data relating to ischemic cardiomyopathy-related mortality in Thailand.

Accordingly, the aim of this study was to establish the first prospective multicenter registry in ischemic cardiomyopathy in Thailand, to determine the 1-year mortality rate, and to identify the factors including type of $\beta$ blockers used, according to the guidelines [11] that significantly predict 1 -year mortality in this patient population.

\section{Methods}

This prospective multicenter registry enrolled consecutive patients diagnosed with ischemic cardiomyopathy at 9 medical centers located across Thailand from December 2014 to November 2015. The protocol for this study was approved by the institutional review boards of all participating centers, and study participants provided written informed consent. This study complied with the principles set forth in the Declaration of Helsinki (1964) and all of its subsequent amendments.

Patients aged greater than 18 years with LV function less than $40 \%$ by echocardiogram, magnetic resonance imaging (MRI), LV ventriculogram, or thallium scan within 1 year were included if they satisfied one or more of the following criteria:

1. Presence of epicardial coronary stenoses $>75 \%$ in the left main or proximal

left anterior descending artery (LAD) by coronary angiogram, and/or presence of two major epicardial coronary stenoses $>75 \%$

2. Prior history of MI

3. Prior history of revascularization by coronary artery bypass graft (CABG) or percutaneous coronary intervention $(\mathrm{PCI})$

4. Magnetic resonance imaging (MRI) pattern compatible with ischemic cardiomyopathy

Patients were excluded if they met one of the following criteria:

1. History of MI within 30 days when assessing LV function

2. History of acute coronary syndrome within 30 days when assessing LV function

3. History of significant valvular stenosis or regurgitation that may explain LV dysfunction

4. Currently enrolled in one or more blinded clinical trials

5. Life expectancy less than 1 year

6. Lost to follow-up

7. Refusal to participate

8. Unstable hemodynamic status

Baseline clinical characteristics, angiographic data, procedural characteristics, and periprocedural events were obtained from patients and patient medical records. Patient data was entered into a case record form 
(CRF) via a web-based system. CRF data was submitted to the Research Unit of the Division of Cardiology, Faculty of Medicine Siriraj Hospital, Mahidol University on the 1st day of every month during the study period. Periodic data verification was performed by primary investigators and nurse coordinators from the Faculty of Medicine Siriraj Hospital. Site monitoring was periodically performed at each site. Patients were followed-up every 6 months for 60 months.

Guideline-recommended $\beta$-blockers were defined as Bisoprolol, Carvediolol, Metoprolol succinate, Nebivolol. Non-guideline-recommended $\beta$-blockers were defined as Atenolol, Metoprolol tartrate, Propanolol [11].

\section{Statistical analysis}

Patient baseline characteristics are presented using descriptive statistics. Continuous variables are expressed as median (minimum, maximum) or mean \pm standard deviation (SD). Categorical variables are expressed as number and percentage. Bivariate analysis of clinical events and baseline, angiographic, and procedural characteristics were performed for categorical variables using the mean of crosstabs, and for continuous variables using comparison of means. Chi-square and Fisher's exact tests were used to compare each characteristic of interest with clinical events. Those results were expressed as number and percentage (\%) for categorical variables, and as mean $\pm \mathrm{SD}$ for continuous variables. A $p$-value less than 0.05 was considered statistically significant. All statistical analyses were performed using SPSS Statistics version 19.0 (SPSS, Inc., Chicago, IL, USA).

\section{Results}

Four hundred and nineteen patients were enrolled. The mean age of patients was $65.08 \pm 11.30$ years, and $73 \%$ were male. The Thailand Universal Coverage Scheme (UCS) (189 patients, 45.1\%) and the Thailand Civil Servant Medical Benefit Scheme (CSMBS) (175 patients, $41.8 \%$ ) accounted for the majority of reimbursement status. More than half of the patients had a history of prior MI (259 patients, 61.8\%). Baseline demographic, clinical, electrocardiographic, and echocardiographic characteristics of patients are shown in Table 1. Two hundred and twenty-six patients $(53.9 \%)$ had history of PCI. Other previous procedures included CABG $(21.5 \%)$ and automated implantable cardioverter-defibrillator (AICD) placement (10.3\%). The mean ejection fraction (EF) was $29.9 \pm 7.7 \%$ by Simpson's method, and $31.6 \pm 9.4 \%$ by Teicholz's method. Mean fasting blood sugar was $118.8 \pm 37.3$ units, mean LDL was $100.2 \pm 44.0 \mathrm{mg} / \mathrm{L}$, and the median NT-proBNP was $1470(38-12,399)$ units. Of the 410 patients who were taking antiplatelet medication, aspirin was the most common (94.4\%), followed by
Table 1 Baseline demographic, clinical, electrocardiographic, and echocardiographic characteristics

\begin{tabular}{|c|c|}
\hline Characteristics & $(N=419)$ \\
\hline \multicolumn{2}{|l|}{ Demographic data } \\
\hline Age (years), mean $\pm S D$ & $65.08 \pm 11.30$ \\
\hline Male, n (\%) & $306(73.0 \%)$ \\
\hline Diabetes, n (\%) & $181(43.2 \%)$ \\
\hline Hypertension, n (\%) & 315 (75.2\%) \\
\hline Chronic kidney disease, n (\%) & $123(29.4 \%)$ \\
\hline Dyslipidemia, n (\%) & $363(86.6 \%)$ \\
\hline Chronic stable angina, n (\%) & $34(8.1 \%)$ \\
\hline History of myocardial infarction, n (\%) & $259(61.8 \%)$ \\
\hline Stroke (ischemic), n (\%) & $38(9.1 \%)$ \\
\hline Peripheral vascular disease, n (\%) & $18(4.3 \%)$ \\
\hline \multicolumn{2}{|l|}{ NYHA FC, n (\%) } \\
\hline 1 & $82(20.6 \%)$ \\
\hline 2 & $238(59.8 \%)$ \\
\hline 3 & $68(17.1 \%)$ \\
\hline 4 & $10(2.5 \%)$ \\
\hline \multicolumn{2}{|l|}{ Electrocardiographic data } \\
\hline Rhythm, n (\%) & $342(87.7 \%)$ \\
\hline Sinus Rhythm, n (\%) & $33(8.5 \%)$ \\
\hline \multicolumn{2}{|l|}{ Atrial fibrillation n (\%) } \\
\hline Rate (bpm), mean \pm SD & $76.4 \pm 18.5$ \\
\hline Systolic Blood pressure $\mathrm{mmHg}$ & $123.5 \pm 20.4$ \\
\hline Diastolic Blood pressure $\mathrm{mmHg}$ & $70.6 \pm 12.7$ \\
\hline \multicolumn{2}{|l|}{ Echocardiographic data } \\
\hline LVEF (\%) by Simpson's method, mean \pm SD & $29.99 \pm 7.68$ \\
\hline LVEF (\%) by Teicholz's method, mean \pm SD & $31.59 \pm 9.42$ \\
\hline LVESD $(\mathrm{mm})$ by M-mode, mean \pm SD & $52.90 \pm 17.04$ \\
\hline LVEDD (mm) by M-mode, median (min, max) & $62.00(0.58,560.00)$ \\
\hline Mitral E wave velocity, mean $\pm \mathrm{SD} \mathrm{m} / \mathrm{s}$ & $70.68 \pm 34.28$ \\
\hline Mitral A wave velocity, mean $\pm S D \mathrm{~m} / \mathrm{s}$ & $65.11 \pm 32.11$ \\
\hline LV thrombus, n (\%) & $20(5.2 \%)$ \\
\hline
\end{tabular}

Abbreviations: SD standard deviation; NYHA FC New York Heart Association Functional Classification; bpm beats per minute; LVEF left ventricular ejection fraction; $L V E S D$ left ventricular end-systolic diameter; $L V E D D$ left ventricular end-diastolic diameter

clopidogrel (40.7\%). Warfarin was prescribed in $17.3 \%$. Seventy-six percent of patients received beta-blockers, of which carvedilol was the most commonly used (228, 71.7\%). $69.2 \%$ of patients received either angiotensin converting enzyme-inhibitor (ACE-I) or angiotensin II receptor blockers (ARB).

\section{One-year clinical outcomes}

Thirty-nine patients $(9.9 \%)$ had died at 1-year with 27 (69.2\%) experiencing cardiovascular death, and 12 (30.8\%) experiencing non-cardiovascular death. Congestive heart 
failure occurred in 31 patients (7.4\%), and non-fatal MI occurred in 6 patients (1.4\%). The causes of cardiovascular death were mostly progressive heart failure, arrhythmia, sudden cardiac death, and fatal MI.

\section{Clinical predictors of 1-year mortality}

Patients were classified into two groups at the 1-year time point - dead (group A) or alive (group B). A comparison of baseline characteristics between groups revealed that a significantly higher proportion of patients in group A had a higher New York Heart Association Functional Classification level than the proportion of patients in group B $(p=0.012)$.

The baseline rhythm demonstrated no impact on 1year mortality; however, mortality was higher among patients with prior inferior myocardial infarction.

Left ventricular ejection fraction (LVEF) was significantly lower in group A than in group B $(26.7 \pm 7.6 \%$ vs. $30.2 \pm 7.8 \%$, respectively; $p=0.021)$. Left ventricular endsystolic volume (LVESV) $(130.9 \pm 56.8 \mathrm{ml}$ vs. $111.6 \pm 50.9$ $\mathrm{ml} ; \quad p=0.046)$, left ventricular end-diastolic volume (LVEDV) $(185.8 \pm 73.2 \mathrm{ml}$ vs. $155.6 \pm 64.2 \mathrm{ml} ; p=0.014)$, and mitral E velocity $(89.7$ vs. $64.1 \mathrm{~m} / \mathrm{s} ; p=0.040)$ were all also higher in group A than in group B. Previous history of cardiovascular symptoms, electrocardiographic findings, and echocardiographic findings between patients in group A and patients in group B is shown in Table 2 .

Medication use compared between patients who died and patients who were alive at 1 year is shown in Table 3. No significant difference was observed between groups for the rate of use of ACE inhibitors, antiplatelets, diuretics, or ivabradine between survivors and those who died at 1 year. Patients in group A had significantly lower statin use $(94.7 \%$ vs. $99.7 \% ; p=0.029)$, despite significantly higher use of non-guidelinerecommended $\beta$-blocker. Patients receiving statin had lower mortality than patients not receiving statin $(9.8 \%$ vs. $66.7 \%$, respectively; $p=0.029$ ) and significantly higher use of non-guideline-recommended $\beta$-blockers. Patients receiving guideline-recommended $\beta$-blocker had lower mortality than patients receiving nonguideline-recommended $\beta$-blocker $(8.1 \%$ vs. $18.2 \%$, respectively; $p=0.050)$. Event rates who received guideline-recommended $\beta$-blockers and patients who received non-guideline-recommended $\beta$-blockers are shown in Fig. 1.

Previous history of cardiovascular intervention shown in Table 4. No significant difference was observed between groups for the rate of use of AICD, cardiac resynchronization therapy (CRT), cardiac resynchronization therapy defibrillator (CRTD), PCI or CABG between survivors and those who died at 1 year.

\section{Discussion}

The 1-year mortality rate among Thai ischemic cardiomyopathy patients in this study was $9.9 \%$. We found baseline New York Heart Association (NYHA), presence of prior inferior MI, higher LVEDV, and mitral E velocity with shortened mitral deceleration time by echocardiogram and Doppler to be predictors of 1-year mortality. Mortality was significantly lower among patients who received guideline-recommended $\beta$-blockers and/or statin.

The 1-year mortality rate reported in this study is lower than the rates reported from two prior US studies $[12,13]$. Mortality was $18 \%$ in the Studies of Left Ventricular Dysfunction (SOLVD) Registry and 16\% in the Duke Databank for Cardiovascular Disease in 1997. The lower mortality rate in the present study is likely due to the impact of guideline-recommended therapy in the current era, and differences in patient demographics and lifestyle. This study also revealed high rates of use of antiplatelets, statins, ACE-I/ARBs, and $\beta$-blockers.

The most important finding from this registry is the difference in mortality rate between patients who received guideline-recommended versus non-guidelinerecommended $\beta$-blockers. Non-guideline-recommended $\beta$-blockers were associated with increased mortality whereas guidelines-recommended $\beta$-blockers were associated with decreased mortality. $\beta$-blockers provide a well-established mortality benefit in patients with LV dysfunction [14]. $\beta$-blockers are currently prescribed in patients with ischemic cardiomyopathy if there is no contraindication. In Thailand, $\beta$-blockers are listed as an essential drug, including both guideline-recommended and non-guideline-recommended $\beta$-blockers. However, due to budget limits in some hospitals only nonguideline-recommended $\beta$-blockers may be provided assuming that the clinical benefits are class effect. The majority of the non-guideline-recommended $\beta$-blockers are generic drugs, so there will likely be no pharmaceutical company sponsored studies conducted to investigate the impact of non-guideline-recommended $\beta$-blockers on mortality.

The Cardiac Insufficiency Bisoprolol Study (CIBIS) and CIBIS II demonstrated mortality benefit of bisoprolol in patients with heart failure, regardless of etiology. Bisoprolol also showed benefit relative to cardiovascular death and all-cause hospitalization [15, 16]. The mortality benefit of carvedilol was demonstrated in the 2002 Carvedilol Prospective Randomized Cumulative Survival (COPERNICUS) trial [17]. The Metoprolol CR/XL Randomised Intervention Trial in Congestive Heart Failure (MERIT-HF) trial demonstrated the mortality reduction benefit of metoprolol succinate, especially in sudden death and death due to progressive pump failure [18]. In contrast to 
Table 2 Comparison of Previous history/findings between patients who died and who alive at 1 year

\begin{tabular}{|c|c|c|c|}
\hline Previous history/findings & $\begin{array}{l}\text { Died } \\
\text { at } 1 \text { year } \\
(n=39)\end{array}$ & $\begin{array}{l}\text { Alive } \\
\text { at } 1 \text { year } \\
(n=357)\end{array}$ & $p$-value \\
\hline Chronic stable angina, n (\%) & $4(10.3 \%)$ & $29(8.1 \%)$ & 0.552 \\
\hline Myocardial infarction, n (\%) & $26(66.7 \%)$ & $221(61.9 \%)$ & 0.560 \\
\hline Peripheral vascular disease, n (\%) & $3(7.7 \%)$ & $12(3.4 \%)$ & 0.175 \\
\hline NYHA FC 1, n (\%) & $4(11.1 \%)$ & $74(21.7 \%)$ & \\
\hline NYHA FC 2, n (\%) & $18(50.0 \%)$ & $209(61.3 \%)$ & 0.012 \\
\hline NYHA FC 3, n (\%) & $12(33.3 \%)$ & $52(15.2 \%)$ & \\
\hline NYHA FC 4, n (\%) & $2(5.6 \%)$ & $6(1.8 \%)$ & \\
\hline Baseline HR (bpm), mean \pm SD & $78.4 \pm 17.1$ & $77.1 \pm 32.6$ & 0.817 \\
\hline Target HR at 1 year (bpm), mean \pm SD & $82.3 \pm 16.3$ & $73.3 \pm 14$ & 0.096 \\
\hline Baseline Systolic Blood Pressure, $\mathrm{mmHg}$ & $115.2 \pm 23.2$ & $124.4 \pm 19.8$ & 0.007 \\
\hline Baseline Diastolic Blood Pressure, $\mathrm{mmHg}$ & $66.9 \pm 11.7$ & $71.2 \pm 12.7$ & 0.044 \\
\hline Systolic Blood pressure at 1 year, $\mathrm{mmHg}$ & $111.8 \pm 11.2$ & $123.2 \pm 19.2$ & 0.094 \\
\hline Diastolic Blood pressure at 1 year, $\mathrm{mmHg}$ & $67 \pm 10.4$ & $70.4 \pm 12$ & 0.423 \\
\hline \multicolumn{4}{|l|}{ Electrocardiographic findings } \\
\hline Sinus Rhythm, n (\%) & $31(83.8 \%)$ & $291(87.7 \%)$ & 0.546 \\
\hline Atrial fibrillation n (\%) & $5(13.5 \%)$ & $28(8.4 \%)$ & \\
\hline Rate (bpm), mean $\pm S D$ & $78.38 \pm 15.65$ & $76.03 \pm 18.90$ & 0.468 \\
\hline PR interval (ms), median (max, min) & $177(104,999)$ & $175(0,909)$ & 0.320 \\
\hline QRS complex duration (ms), mean \pm SD & $114.35 \pm 30.77$ & $113.64 \pm 27.51$ & 0.883 \\
\hline Inferior leads (II or III or aVF), n (\%) & $14(63.6 \%)$ & $88(42.1 \%)$ & 0.053 \\
\hline Anterior leads (I or aVL), n (\%) & $2(9.1 \%)$ & $35(16.7 \%)$ & 0.542 \\
\hline Lateral leads (V2-V5), n (\%) & $14(63.6 \%)$ & $150(71.8 \%)$ & 0.424 \\
\hline \multicolumn{4}{|l|}{ Echocardiographic findings } \\
\hline LVEF (\%) by Simpson's method, mean \pm SD & $26.7 \pm 7.6$ & $30.2 \pm 7.8$ & 0.021 \\
\hline LVESV, mean \pm SD ml & $130.96 \pm 56.83$ & $111.63 \pm 50.98$ & 0.046 \\
\hline LVEDV, mean \pm SD ml & $185.8 \pm 73.2$ & $155.6 \pm 64.2$ & 0.014 \\
\hline LVEF (\%) by Teicholz's method, mean \pm SD & $29.27 \pm 10.70$ & $32.01 \pm 9.25$ & 0.098 \\
\hline Mitral E wave velocity units, median ( $\max , \mathrm{min}) \mathrm{m} / \mathrm{s}$ & $89.7(11.1,250)$ & $64.1(0.32,167)$ & 0.040 \\
\hline Mitral A wave velocity, median ( $\max , \mathrm{min}) \mathrm{m} / \mathrm{s}$ & $61.6(5.68,124.2)$ & $66.1(0.32,149)$ & 0.753 \\
\hline Mitral deceleration time, mean \pm SD ms & $142.9 \pm 57.5$ & $182.4 \pm 85.7$ & 0.041 \\
\hline RVSP $\mathrm{mmHg}$, mean $\pm \mathrm{SD}$ & $45.58 \pm 18.45$ & $40.64 \pm 17.42$ & 0.186 \\
\hline LV thrombus, n (\%) & $3(8.3 \%)$ & $15(4.5 \%)$ & 0.402 \\
\hline
\end{tabular}

A $p$-value $<0.05$ indicates statistical significance

Abbreviations: NYHA FC New York Heart Association Functional Classification; bpm beats per minute; SD standard deviation; ms milliseconds; LBBB left bundle branch block; LVEF left ventricular ejection fraction; LVESV left ventricular end-systolic volume; LVEDV left ventricular end-diastolic volume; RVSP right ventricle systolic pressure

the benefits of metoprolol succinate on death, metoprolol tartrate demonstrated only quality of life benefit and exercise capacity benefit in the Metoprolol in Dilated Cardiomyopathy (MDC) trial [19]. Uncertainty as to whether there were class effects of $\beta$-blockers was increased by the findings in the Carvedilol Or Metoprolol European Trial (COMET) study [20]. Each $\beta$-blocker has different sympatholytic effects on $\beta 1$, $\beta 2, \beta 3$ and $\alpha$ receptors. Carvediolol has $\alpha 1, \beta 1$ and $\beta 2$ antagonist activity. They also differ in their lipophilicity, and membrane stabilizing effects. Nebivolol is a beta-1-selective betablocker with vasodilating properties related to nitric oxide modulation that reduce peripheral vascular resistance [21]. Metoprolol succinate has more even beta-blockade over $24 \mathrm{~h}$ compare with immediate release Metoprolol tartrate and the target dose can be increased to $200 \mathrm{mg}$ once per day compare with $50 \mathrm{mg}$ three times per day [22]. These 
Table 3 Comparison of baseline medication between patients who died and who were alive at 1 year

\begin{tabular}{llll}
\hline Medications & $\begin{array}{l}\text { Died at 1 year } \\
(n=39) \\
\mathrm{n}(\%)\end{array}$ & $\begin{array}{l}\text { Alive at 1 year } \\
(n=357)\end{array}$ & $\begin{array}{c}p \text {-value } \\
\mathrm{n}(\%)\end{array}$ \\
\hline Antiplatelet & $37(94.9 \%)$ & $350(98.0 \%)$ & 0.219 \\
Aspirin & $34(91.9 \%)$ & $332(94.9 \%)$ & 0.439 \\
Clopidogrel & $13(35.1 \%)$ & $143(40.9 \%)$ & 0.500 \\
Ticagrelor & $2(5.4 \%)$ & $7(2.0 \%)$ & 0.209 \\
Warfarin & $9(24.3 \%)$ & $58(16.6 \%)$ & 0.236 \\
Beta-blocker & $29(74.4 \%)$ & $273(76.5 \%)$ & 0.769 \\
Bisoprolol & $1(3.4 \%)$ & $34(12.5 \%)$ & 0.223 \\
Metoprolol succinate & $0(0.0 \%)$ & $6(2.2 \%)$ & 1.000 \\
Metoprolol tartrate & $5(17.2 \%)$ & $24(8.8 \%)$ & 0.176 \\
Carvedilol & $20(69.0 \%)$ & $197(72.2 \%)$ & 0.716 \\
Nebivolol & $0(0.0 \%)$ & $0(0.0 \%)$ & - \\
Atenolol & $1(3.4 \%)$ & $10(3.7 \%)$ & 1.000 \\
Propranolol & $2(6.9 \%)$ & $2(0.7 \%)$ & 0.047 \\
Non-guideline-recommended & $8(27.6 \%)$ & $36(13.2 \%)$ & 0.050
\end{tabular}

beta-blocker (metoprolol tartrate or atenolol or propanolol)

\begin{tabular}{llll} 
ACE inhibitors & $16(41.0 \%)$ & $154(43.1 \%)$ & 0.800 \\
ARB & $11(28.2 \%)$ & $99(27.7 \%)$ & 0.950 \\
Nitrates & $12(30.8 \%)$ & $116(32.5 \%)$ & 0.827 \\
Hydralazine & $3(7.7 \%)$ & $34(9.5 \%)$ & 1.000 \\
Trimetazidine & $3(7.7 \%)$ & $26(7.3 \%)$ & 1.000 \\
Ivabradine & $3(7.7 \%)$ & $8(2.2 \%)$ & 0.084 \\
Diuretics & $30(76.9 \%)$ & $255(71.4 \%)$ & 0.468 \\
Digitalis & $7(17.9 \%)$ & $42(11.8 \%)$ & 0.302 \\
Statins & $36(94.7 \%)$ & $333(99.7 \%)$ & 0.029 \\
Insulin & $8(57.1 \%)$ & $47(41.2 \%)$ & 0.256 \\
Sulfonylureas & $4(28.6 \%)$ & $57(50.0 \%)$ & 0.130 \\
Biguanides & $6(42.9 \%)$ & $52(45.6 \%)$ & 0.845 \\
Thiazolidinediones & $0(0.0 \%)$ & $3(2.6 \%)$ & 1.000 \\
\hline A P-value< 0.05 Inc
\end{tabular}

A $p$-value $<0.05$ indicates statistical significance Abbreviations: $A C E I$ angiotensin-converting enzyme inhibitors; $A R B$ angiotensin receptor blockers

differences in pharmacologic properties may lead to different outcomes in heart failure patients.

There is limited evidence that supports the use of non-guideline-recommended $\beta$-blockers, such as propranolol or atenolol, for mortality reduction in patients with ischemic cardiomyopathy and reduced EF.

Our comparisons between guideline-recommended and non-guideline-recommended $\beta$-blocker found mortality to be significantly lower in patients who received guideline-recommended $\beta$-blocker, even though there was no difference between groups for either target heart rate or blood pressure. The results of this study emphasize the importance of selecting $\beta$ - blockers that are evidence-based and guidelinerecommended.

From a healthcare cost standpoint, non-guidelinerecommended $\beta$-blockers are more affordable, but the cost of overall treatment is likely to be higher, because non-guideline-recommended $\beta$-blockers do not significantly reduce cardiovascular events and death. The findings in this study in relation to the type of $\beta$-blocker that should be used in this ischemic cardiomyopathy will be of benefit to both clinicians and healthcare policymakers. This study supports the concept that only guideline-recommended $\beta$-blockers should be prescribed for patients with ischemic cardiomyopathy. These data also strongly suggests that these drugs should be approved for inclusion on the drug lists of Thailand's healthcare coverage schemes.

We found NYHA class to be a significant predictor of 1 -year mortality, which is similar to the results of two prior studies [23, 24]. Van de Broek SA, et al. found NYHA class and peak oxygen consumption (VO2) to be significantly worse in stable NYHA class II and III heart failure patients with LVEF $<40 \%$ who died within a 2year follow-up period [23]. Coronary artery disease, LVEF, and NYHA III are independent predictors of mortality in the patients with mild to moderate symptomatic heart failure as reported by Scrutinio D et al. [24].

Interestingly, we found a trend for the presence of inferior MI but not anterior MI to predict death by 1 year $(p=0.052)$. This may be explained by a bias caused by our inclusion criteria that defined ischemic cardiomyopathy by presence of epicardial coronary stenoses greater than $75 \%$ in the left main or proximal left anterior descending artery (LAD), and/or presence of two major epicardial coronary stenoses $>75 \%$. Therefore, the majority of patients enrolled in our study had coronary stenoses of LAD or infarction in the anterior wall territory by inclusion criteria. The additional presence of inferior infarction may influence mortality due to a larger area of MI involvement.

LVEF was also found to be a significant predictor of 1year mortality as previously described [13, 25]. Left ventricular end-diastolic volume was also significantly higher in patients with 1-year mortality. Several echocardiographic hemodynamic parameters predicted 1-year mortality. Elevation of mitral E velocity, indicating markedly elevated left ventricular end-diastolic pressure (LVEDP) and high left atrial pressure, was significantly higher in patients who died.

Patients with low ejection fractions have diastolic dysfunction as their reduction in LV function progresses. In contrast to the reverse E/A ratio that survivors had at 1 year, the patients that had died had pseudo normalization of E/A ratio. By just looking at the pattern of E/A ratio may be confusing. The mitral deceleration 


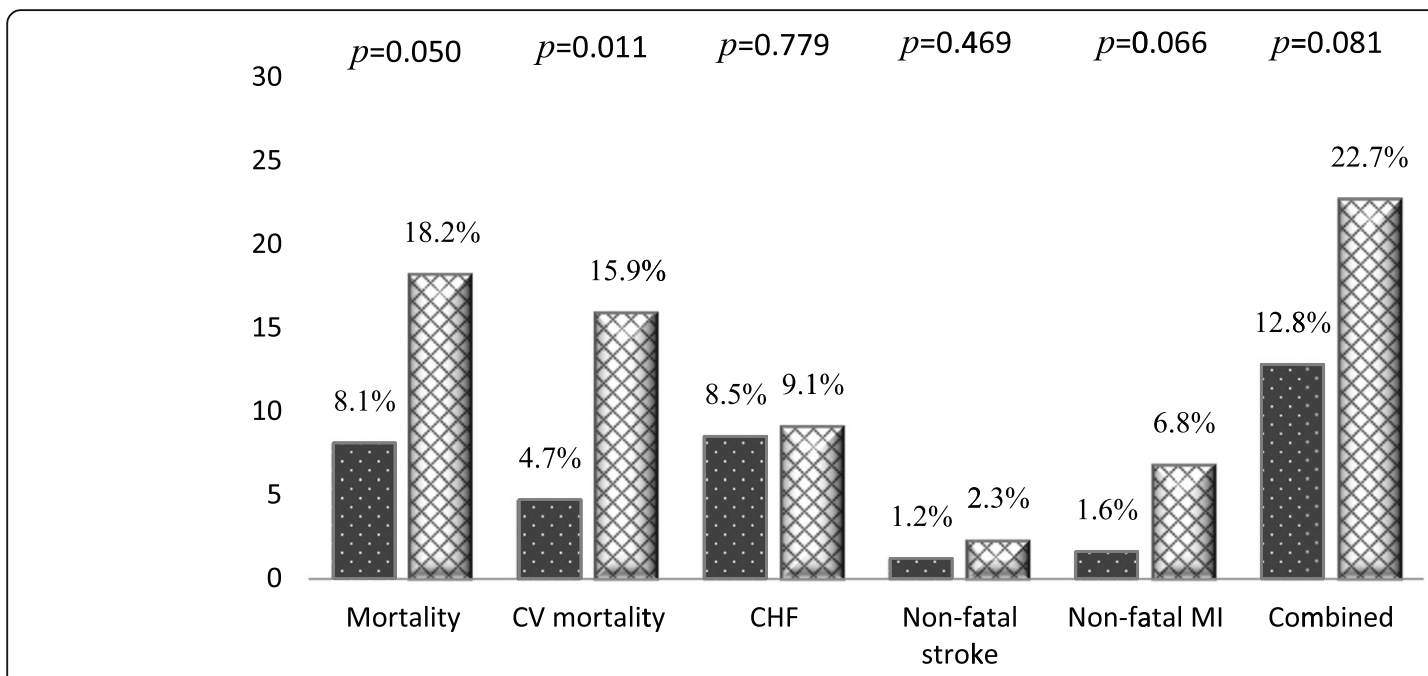

Guideline-recommended beta-blocker Non-guideline-recommended beta-blocker

Fig. 1 Event rates of all-cause mortality, cardiovascular (CV) mortality, congestive heart failure (CHF), non-fatal stroke, and non-fatal myocardial infarction (MI) in patients who received guideline-recommended $\beta$-blockers and patients who received non-guideline-recommended $\beta$-blockers The use of non-guideline-recommended $\beta$-blockers rather than guideline recommended $\beta$-blockers were associated with increased with 1-year CV mortality $(P<0.05)$

time helps interpreting hemodynamic parameters. Mitral valve deceleration time is a noninvasive Doppler echocardiographic parameter that evaluates left ventricular filling pressure, and has been shown to correlate well with pulmonary capillary wedge pressure in patients with reduced left ventricular EF [26]. Also the usefulness of the echocardiographic mitral flow velocities curves has been shown for estimating left ventricular filling pressure in patients with left ventricular dysfunction [27]. Mitral deceleration time $<140 \mathrm{~ms}$ predicts cardiovascular mortality in acute MI $[28,29]$. In the present study, all patients that died by the 1-year follow-up had a mitral deceleration time of less than $150 \mathrm{~ms}$. High mitral $\mathrm{E}$ velocity with a short mitral deceleration time

Table 4 Comparison of previous history of cardiovascular intervention between patients who died and who were alive at 1 year

\begin{tabular}{llll}
\hline Cardiovascular intervention & $\begin{array}{l}\text { Died at 1 year } \\
(n=39) \\
\mathrm{n}(\%)\end{array}$ & $\begin{array}{l}\text { Alive at 1 year } \\
(n=357) \\
\mathrm{n}(\%)\end{array}$ & $p$-value \\
\hline AICD & $4(10.3 \%)$ & $38(10.6 \%)$ & 1.000 \\
CRT & $0(0 \%)$ & $1(0.3 \%)$ & 1.000 \\
CRTD & $1(2.6 \%)$ & $9(2.5 \%)$ & 1.000 \\
AICD/CRT/CRTD & $5(12.8 \%)$ & $48(13.4 \%)$ & 0.913 \\
PCI & $16(41.0 \%)$ & $197(55.2 \%)$ & 0.092 \\
CABG & $9(23.1 \%)$ & $79(22.1 \%)$ & 0.892 \\
\hline A p-value< 0.05 indican
\end{tabular}

A $p$-value $<0.05$ indicates statistical significance Abbreviations: AICD automated implantable cardioverter defibrillator; CRT cardiac resynchronization therapy; CRTD cardiac resynchronization therapy defibrillator; $P C l$ percutaneous coronary intervention; $C A B G$ coronary artery bypass graft demonstrates a restrictive pattern. The patients who died had pseudo normalization of the E/A ratio with a restrictive pattern of mitral deceleration time indicating further progression of diastolic dysfunction. Combining mitral deceleration time with E/A ratio also predicted 1year mortality. In this study, we identified echocardiographic and hemodynamic parameters that indicate markedly elevated left ventricular pressure, elevated left atrial pressure, elevated mitral E velocity, and shortened mitral deceleration time. All of these parameters were shown to significantly predict 1 -year mortality.

\section{Conclusions}

The results of this study revealed a $9.9 \%$ mortality rate among Thai patient with ischemic cardiomyopathy. The Doppler echocardiographic parameters that were found to be significantly associated with 1-year mortality were LVEF, LVEDV, mitral E velocity, and mitral valve deceleration time. The use of non-guideline-recommended $\beta$ blockers was associated with increased 1-year mortality.

\footnotetext{
Abbreviations

ACEl: Angiotensin converting enzyme-inhibitor; AICD: Automated implantable cardioverter-defibrillator; ARB: Angiotensin II receptor blockers; CABG: Coronary artery bypass graft; CAD: Coronary artery disease; CHF: Congestive heart failure; CIBIS: The cardiac insufficiency Bisoprolol study; COMET: The Carvedilol or Metoprolol European trial; COPERNICUS: Carvedilol prospective randomized cumulative survival; CRF: Case record form; CSMBS: Thailand civil servant medical benefit scheme; LAD: Left anterior descending artery; LV: Left ventricular; LVEDP: Left ventricular end-diastolic pressure; LVEDV: Left ventricular end-diastolic volume; LVEF: Left ventricular ejection fraction; LVESV: Left ventricular end-systolic volume; MDC: The Metoprolol in dilated cardiomyopathy; MERIT-HF: The Metoprolol CR/XL randomised intervention trial in congestive heart failure; MI: Myocardial
} 
infarction; MRI: Magnetic resonance imaging; NYHA: New York heart association; PCl: Percutaneous coronary intervention; SD: Standard deviation; SOLVD: The studies of left ventricular dysfunction; STEMI: ST-elevation myocardial infarction; UCS: The Thailand universal coverage scheme

\section{Acknowledgements}

The authors gratefully acknowledge Sutipong Udompanthurak of the Division of Clinical Epidemiology, Department of Research and Development, Faculty of Medicine Siriraj Hospital for assistance with statistical analysis, and the research coordinators from all participating centers for their dedicated support.

\section{Conflict of interest declaration}

All authors declare no personal or professional conflicts of interest, and no financial support from the companies that produce and/or distribute the drugs, devices, or materials described in this report.

\section{Authors' contributions}

NW contributed to conception and designed the study, participated in the performance of the research, statistical data analysis and interpretation, drafted and revised manuscript, and gave final approval. SS participated in the performance of the research, gave final approval. $\pi$ participated in the performance of the research, gave final approval. PN participated in the performance of the research, gave final approval. AP participated in the performance of the research, gave final approval. KJ participated in the performance of the research, gave final approval. $\Pi$ participated in the performance of the research, gave final approval. KB participated in the performance of the research, gave final approval. PK participated in the performance of the research, gave final approval. RK contributed to conception, revised manuscript, gave final approval. RP participated in the performance of the research, statistical data analysis and interpretation, gave final approval. HW substantively revised manuscript and gave final approval. All authors read and approved the final manuscript.

\section{Funding}

This study was supported by the Research Division Faculty of Medicine Siriraj, Mahidol University, Bangkok, Thailand [grant number. R015834003], and Health Systems Research Institute (HSRI), Nonthaburi, Thailand [grant no. 59-009]. They had no role in the design of the study and collection, analysis, and interpretation of data and in writing the manuscript.

\section{Availability of data and materials}

The datasets used and/or analysed during the current study are de-identified and available from the corresponding author on reasonable request. Identifying/confidential patient data should not be shared.

\section{Ethics approval and consent to participate}

The protocol for this study was approved by the institutional review boards of all participating centers (Local Ethics Committee including Siriraj Institutional Review Board, Ethical Clearance Committee on Human Rights Related to Research Involving Human Subjects Faculty of Medicine Ramathibodi Hospital, The Human Research Ethics Committee of Thammasat University, Institutional Review Board Faculty of Medicine Chulalongkorn University, Chiang Mai University Research Ethic Committee) and other participating centers were approved by The Ethical Review Committee for Research in Human Subjects Ministry of Public Health, Thailand. All study participants provided written informed consent.

\section{Consent for publication}

\section{Not applicable.}

\section{Competing interests}

The authors declare that they have no competing interests.

\section{Author details}

${ }^{1}$ Division of Cardiology, Department of Medicine, Faculty of Medicine Siriraj Hospital, Mahidol University, 2 Wanglang Road, Bangkoknoi, Bangkok 10700, Thailand. ${ }^{2}$ Department of Medicine, Faculty of Medicine, Chulalongkorn University, Bangkok, Thailand. ${ }^{3}$ Department of Medicine, Buddhachinaraj Hospital, Phitsanulok, Thailand. ${ }^{4}$ Department of Medicine, Chonburi Hospital, Chonburi, Thailand. ${ }^{5}$ Department of Internal Medicine, Faculty of Medicine,
Chiang Mai University, Chiang Mai, Thailand. 'Department of Medicine, Surat Thani Hospital, Surat Thani, Thailand. ${ }^{7}$ Department of Internal Medicine, Faculty of Medicine Ramathibodi Hospital, Mahidol University, Bangkok, Thailand. ${ }^{8}$ Faculty of Medicine, Thammasat University Hospital, Pathum Thani, Thailand. ${ }^{9}$ Department of Internal Medicine, Maharaj Nakhon Ratchasima Hospital, Nakhon Ratchasima, Thailand. ${ }^{10}$ Her Majesty's Cardiac Center, Faculty of Medicine Siriraj Hospital, Mahidol University, Bangkok, Thailand.

${ }^{11}$ Green Lane Cardiovascular Service, Auckland City Hospital, Auckland, New Zealand.

Received: 29 July 2019 Accepted: 18 December 2019 Published online: 09 January 2020

\section{References}

1. Burch GE, Giles TD, Colcolough HL. Ischemic cardiomyopathy. Am Heart J. 1970;79:291-2.

2. Rahimtoola SH. The hibernating myocardium. Am Heart J. 1989;117:211-21.

3. Rahimtoola SH. A perspective on three large multicenter randomized clinical trials of coronary bypass surgery for chronic stable angina. Circulation. 1985:72:V123

4. McNamara R, Wang Y, Herrin J, et al. Effect of door-to-balloon time on mortality in patients with ST segment elevation myocardial infarction. JACC. 2006:47:2180-6.

5. Brodie B, Stone G, Morice M, et al. Importance of time to reperfusion on outcomes with primary coronary angioplasty for acute myocardial infarction (results from the stent primary angioplasty in myocardial infarction trial). Am J Card. 2001;88:1085-90.

6. Brodie B, Hansen C, Stuckey $T$, et al. Door-to-balloon time with primary percutaneous coronary intervention for acute myocardial infarction impacts late cardiac mortality in high risk patients and patients presenting early after the onset of symptoms. JACC. 2006;47:289-95.

7. Giuseppe D, Suryapranata H, Zijlstra F, et al. Symptom-onset-to-balloon time and mortality in patients with acute myocardial infarction treated by primary angioplasty. JACC. 2003;42:991-7.

8. Brodie B, Stone G, Cox D, et al. Impact of treatment delays on outcomes of primary percutaneous coronary intervention for acute myocardial infarction: analysis from the CARDILLAC trial. Am Heart J. 2006;151:1231-8.

9. Wongpraparut N, Chotivoraniyakul C, Panchavinin P, et al. First medical contact to device time in the Thailand national PCl registry. J Med Assoc Thail. 2014;97(12):1247-53.

10. Velazquez EJ, Lee $\mathrm{KL}$, Deja MA, et al. Coronary-artery bypass surgery in patients with left ventricular dysfunction. N Engl J Med. 2011;364:1607-16.

11. Ponikowski P, Voors AA, Anker SD, et al. 2016 ESC guidelines for the diagnosis and treatment of acute and chronic heart failure: the task force for the diagnosis and treatment of acute and chronic heart failure of the European Society of Cardiology (ESC)developed with the special contribution of the heart failure association (HFA) of the ESC. Eur Heart J. 2016:37:2129-200

12. Pagley PR, Beller GA, Watson DD, et al. Improved outcome after coronary bypass surgery in patients with ischemic cardiomyopathy and residual myocardial viability. Circulation. 1997;96:793-802.

13. The SOLVD. Investigators. Effect of Enalapril on Survival in Patients with Reduced Left Ventricular Ejection Fractions and Congestive Heart Failure NEJM. 1991;325:293-302.

14. Lechat $P$, Packer M, Chalon $S$, et al. Clinical effects of beta-adrenergic blockade in chronic heart failure: a meta-analysis of double-blind, placebocontrolled, randomized trials. Circulation. 1998;98:1184-91.

15. CIBIS Investigators and Committees. A randomized trial of beta-blockade in heart failure.The Cardiac Insufficiency Bisoprolol Study(CIBIS). Circulation. 1994;90:1765-73.

16. CIBIS-II Investigators and Committees. The Cardiac Insufficiency Bisoprolol Study II (CIBIS-II): a randomised trial. Lancet. 1999;353:9-13.

17. Packer M, Coats AJ, Fowler MB, et al. Effect of carvedilol on survival in severe chronic heart failure. NEJM. 2001;344:1651-8.

18. MERIT-HF Study Group. Effect of metoprolol CR/XL in chronic heart failure: Metoprolol CR/XL randomised intervention trial in congestive heart failure (MERIT- HF). Lancet. 1999;353:2001-7.

19. Waagstein F, Bristow MR, Swedberg K, et al. Beneficial effects of metoprolol in idiopathic dilated cardiomyopathy. Metoprolol in dilated cardiomyopathy (MDC) trial study group. Lancet. 1993;342:1441-6. 
20. Poole-Wilson PA, Swedberg K, Cleland JG, et al. Comparison of carvedilol and metoprolol on clinical outcomes in patients with chronic heart failure in the Carvedilol or Metoprolol European trial(COMET): randomised controlled trial. Lancet. 2003;362:7-13.

21. Flather MD, Shibata MC, Coats AJ, et al. Randomized trial to determine the effect of nebivolol on mortality and cardiovascular hospital admission in elderly patients with heart failure (SENIORS). EHJ. 2005;26:215-25.

22. Hjalmarson A, Goldstein S, Fagerberg B, et al. Effects of controlled-release metoprolol on total mortality, hospitalizations, and well-being in patients with heart failure: the Metoprolol CR/XL Randomized Intervention Trial in congestive heart failure (MERIT-HF). MERIT-HF Study Group. JAMA. 2000;283: 1295-302.

23. Van den Broek SA, Van Veldhuisen DJ, de Graeff PA, et al. Comparison between New York heart association classification and peak oxygen consumption in the assessment of functional status and prognosis in patients with mild to moderate chronic congestive heart failure secondary to either ischemic or idiopathic dilated cardiomyopathy. AJC. 1992;70:359-63.

24. Scrutinio D, Lagioia R, Ricci A, et al. Prediction of mortality in mild to moderately symptomatic patients with left ventricular dysfunction. The role of the New York heart association classification, cardiopulmonary exercise testing, two-dimensional echocardiography and Holter monitoring. Eur $\mathrm{H} \mathrm{J}$. 1994:15:1089-95.

25. Johnson G, Carson P, Francis GS, et al. Influence of pre-randomization (baseline) variables on mortality and on the reduction of mortality by enalapril. Veterans Affairs Cooperative Study on Vasodilator Therapy of Heart Failure (V-HeFT II). V-HeFT VA Cooperative Studies Group. Circulation. 1993; 87(6 suppl):V132-9.

26. Oh J, Hatle L, Tajik AJ, et al. Diastolic heart failure can be diagnosed by comprehensive two-dimensional and Doppler echocardiography. JACC. 2006;47:500-6.

27. Nishimura RA, Appleton CP, Redfield MM, et al. Noninvasive Doppler echocardiographic evaluation of left ventricular filling pressures in patients with cardiomyopathies: a simultaneous Doppler echocardiographic and cardiac catheterization study. JACC. 1996;28:1226-33.

28. Moller JE, Sondergaard E, Seward JB, et al. Ratio of left ventricular peak Ewave velocity to flow propagation velocity assessed by color M-mode Doppler echocardiography in first myocardial infarction: prognostic and clinical implications. JACC. 2000;35:363-70.

29. Nijland F, Kamp O, Karreman AJ, et al. Prognostic implications of restrictive left ventricular filling in acute myocardial infarction: a serial Doppler echocardiographic study. JACC. 1997;30:1618-24.

\section{Publisher's Note}

Springer Nature remains neutral with regard to jurisdictional claims in published maps and institutional affiliations.

Ready to submit your research? Choose BMC and benefit from:

- fast, convenient online submission

- thorough peer review by experienced researchers in your field

- rapid publication on acceptance

- support for research data, including large and complex data types

- gold Open Access which fosters wider collaboration and increased citations

- maximum visibility for your research: over $100 \mathrm{M}$ website views per year

At $\mathrm{BMC}$, research is always in progress.

Learn more biomedcentral.com/submissions 